Pesq. Vet. Bras. 36(8):724-730, agosto 2016

DOI: $10.1590 / \mathrm{S} 0100-736 \mathrm{X} 2016000800008$

\title{
Investigação clínica e comparação do esfregaço sanguíneo e PCR para diagnóstico de hemoparasitas em equinos de esporte e tração (carroceiros) ${ }^{1}$
}

\begin{abstract}
Renata G.S. Dória*, Daniele Passarelli², Thaís N. Chequer², Gustavo M. Reginato², Yumi B. Hayasaka ${ }^{2}$, Paulo Fantinato Neto $^{2}$, Renan Grigoletto ${ }^{2}$ e Silvio H. Freitas ${ }^{2}$

ABSTRACT.- Dória R.G.S., Passarelli D., Chequer T.N., Reginato G.M., Hayasaka Y.B., Fantinato Neto P., Grigoletto R. \& Freitas S.H. 2016. [Clinical investigation and comparison of blood smear and PCR to diagnose haemoparasites in Sports Horses and Traction Horses (Cart Horses).] Investigação clínica e comparação do esfregaço sanguíneo e PCR para diagnóstico de hemoparasitas em equinos de esporte e tração (carroceiros). Pesquisa Veterinária Brasileira 36(8):724-730. Departamento de Medicina Veterinária, Faculdade de Zootecnia e Engenharia de Alimentos, Universidade de São Paulo, Rua Duque de Caxias Norte 225, Pirassununga, SP 13635-900, Brazil. E-mail: redoria@usp.br

The blood profile is usually explored in equine medicine to find changes not detected through clinical examination. The haematozoa search in horses, often presents conflicting results between the clinical picture presented by the animal and the laboratory result, raising the hypothesis that the hematozoa search technique is responsible for diagnostic failures. Thus, this study aims to compare the values obtained from blood tests in 15 sports horses and 15 traction horses (cart horses), taking into account differences such as nutritional characteristics, state of health and type of activity performed, and to compare the different techniques with hematozoa search, as blood smear and PCR. It was found that only the traction horses showed mean values of red blood cells, hematocrit and hemoglobin below the considered physiological for the species, although $100 \%$ of the animals of both experimental groups were considered positive for hemoparasitoses by PCR. It was verified the superiority of hemoparasites search method by PCR, compared with blood smear performed by different techniques, since only $33.3 \%$ of the horses were considered positive for Theileria equi by this technique, while the PCR showed $100 \%$ positive for Theileria equi, Babesia caballi and mixed infection. None of the animals studied was diagnosed with Anaplasma phagocytophilum (Ehrlichia equi) and Ehrlichia risticcii (Neoricketsia risticii). It is shown that many cases of hemoparasitosis absence of diagnostic by hematological exams and or blood smears are erroneous due to the low sensitivity of the technique and may impact on treatment failure or spread of blood parasites and hemoparasitoses. It is noteworthy to stres the importance of tests such as PCR for the definitive diagnosis.
\end{abstract}

INDEX TERMS: Blood smear, hematology, horse, PCR (polymerase chain reaction).

RESUMO-- Na clínica médica de equinos, explora-se o perfil hematológico do animal, geralmente, com a finalidade de encontrar alterações que não foram constatadas ao exame clínico. A pesquisa de hematozoários em equinos, muitas

\footnotetext{
${ }^{1}$ Recebido em 11 de junho de 2015.

Aceito para publicação em 31 de maio de 2016.

${ }^{2}$ Departamento de Medicina Veterinária, Faculdade de Zootecnia e Engenharia de Alimentos, Universidade de São Paulo (USP), Rua Duque de Caxias Norte 225, Pirassununga, SP 13635-900, Brasil. *Autor para correspondência: redoria@usp.br
}

vezes, apresenta resultados conflitantes entre o quadro clínico apresentado pelo animal e o resultado laboratorial, levantando a hipótese de que a técnica de pesquisa de hematozoários seja a responsável por falhas diagnósticas. Este estudo visa comparar os valores obtidos em exames hematológicos de 15 equinos de esporte e 15 equinos de tração (carroceiros), levando-se em consideração diferenças como características nutricionais, estado de higidez e tipo de atividade realizada, e comparar as diferentes técnicas de pesquisa de hematozoários, como esfregaço sanguíneo e PCR. 
Verificou-se que apenas os equinos de tração apresentaram valores médios de hemácias, hematócrito e hemoglobina abaixo do considerado fisiológico para a espécie, embora $100 \%$ dos animais, de ambos os grupos experimentais, tenham sido considerados positivos para hemoparasitoses por PCR. Verifica-se a superioridade do método de pesquisa de hemoparasitas por PCR, em comparação com esfregaço sanguíneo, realizado por diferentes técnicas, visto que apenas 33,3\% dos animais foram considerados positivos para Theileria equi por esta técnica, enquanto que o PCR revelou $100 \%$ de positividade, para Theileria equi, Babesia caballi e infecção mista. Nenhum dos animais estudados foi diagnosticado com Anaplasma phagocytophilum (Ehrlichia equi) e Ehrlichia risticcii (Neoricketsia risticii). Verifica-se, então, que muitos dos diagnósticos de ausência de hemoparasitose por exame hematológico e ou esfregaço sanguíneo são errôneos, devido à baixa sensibilidade da técnica e podem repercutir em falha no tratamento ou disseminação dos hemoparasitos e das hemoparasitoses. Ressalta-se, então, a importância de exames como o PCR na elaboração de diagnóstico definitivo.

TERMOS DE INDEXAÇÃO: Equinos, esfregaço sanguíneo, hematologia, PCR (reação em cadeia da polimerase).

\section{INTRODUÇÃO}

A equideocultura brasileira é representada por uma variedade de raças nacionais e importadas, as quais são adequadas ao tipo de serviço que irão proporcionar. Os equinos possuem diversas utilidades, dentre elas se destacam a prática de esportes e a tração de veículos (charretes, carroças, arados, por exemplo) (Everton et al. 2011).

Na clínica médica, explora-se o perfil hematológico do animal, geralmente, com a finalidade de encontrar alterações que não foram constatadas ao exame clínico (Sakai et al. 2009). Vale lembrar que a maioria dos estudos sobre perfil hematológico de equídeos tem sido realizada em animais de elite, raças puras, alimentados adequadamente, mantidos em condições padronizadas, submetidos a exercícios e carga de trabalho controlados (Veiga et al. 2006, Ribeiro et al. 2008), enquanto que ainda são escassos os estudos com animais mestiços, utilizados para tração, que trabalham diariamente em condições precárias de nutrição e higidez, como os cavalos carroceiros. Ressalta-se, então, a necessidade de se conhecer as variações dos valores nos parâmetros hematológicos para esses animais, a fim de se estabelecer valores de referência adequados para equinos desta categoria.

Além dos parâmetros hematológicos, outro exame laboratorial realizado, é a pesquisa de hematozoários. Dentre as enfermidades que mais afetam os equinos, destacam-se as doenças parasitárias, onde as hemoparasitoses, como a babesiose equina, denominada de piroplasmose ou nutaliose, causada pelos protozoários hemoparasitas Theileria equi e Babesia caballi (Nizoli et al. 2006, Becker et al. 2007) e a anaplasmose granulocítica equina, conhecida antigamente como erlichiose granulocítica equina, causada pelo hemoparasita Anaplasma phagocytophilus, bactéria gram-negativa intracelular obrigatória (Paz \& Silva et al. 2009), têm sido mencionados como importantes causas de danos à sanidade animal com comprometimento da função equina (Sakai et al. 2009). 0 diagnóstico das hemoparasitoses, normalmente, é feito por meio da observação ao microscópio óptico de esfregaço sanguíneo, colhido de sangue da veia jugular ou de sangue periférico (vasos da face ou orelha). Muitas vezes, o laudo laboratorial para hemoparasitoses é negativo embora o animal esteja doente, o que se justifica pelo fato da não observação do hemoparasito na lâmina confeccionada. Em estudo realizado por Stobbe (1990) e Stobbe et al. (1992) e repetido, em equinos, por Dantas et al. (2011), demonstra-se que o método de confecção do esfregaço a partir do sangue coagulado é um método mais eficaz para diagnóstico e acompanhamento das hemoparasitoses.

Como se vê, até recentemente, a técnica laboratorial mais utilizada para detecção da infecção por hemoparasitos era a visualização microscópica dos parasitos em esfregaços sanguíneos corados. Devido a baixa sensibilidade deste método, testes imunológicos indiretos e métodos diretos como a Reação em Cadeia da Polimerase - PCR (Polymerase Chain Reaction) tem sido incorporados com sucesso na rotina de laboratórios veterinários (Maroso et al. 2002, Golynski et al. 2008, Salvagni et al. 2010, Leal et al., 2011, Abedi et al., 2014, Laus et al. 2015, Malekifard et al. 2014, Posada-Guazmán et al. 2015, Sgorbini et al. 2015). Provas sorológicas, como a Reação de Imunofluorescência Indireta (RIFI) e o Ensaio Imunoenzimático (ELISA) acusam que o animal teve contato com o agente em alguma fase da vida, mas não necessariamente que são animais doentes, podendo ou não estar com o agente no seu organismo no momento da colheita, induzindo a ativação do sistema imunológico (Parra 2009, Abedi et al. 2014, Laus et al. 2015, Sgorbini et al. 2015). A técnica de PCR tem sido amplamente utilizada e reportada na literatura como método que visa à investigação do DNA do agente causador da doença na amostra testada, sendo considerado método direto com maior sensibilidade que a microscopia (Bashiruddin et al. 1999, Leal et al. 2011, Abedi et al. 2014, Laus et al. 2015, Malekifard et al. 2014, Posada-Guazmán et al. 2015, Sgorbini et al. 2015), apresentando maior eficácia comparado aos demais métodos de diagnóstico para as enfermidades em questão. O PCR identifica o DNA ou RNA de uma sequência do genoma do patógeno e é extremamente sensível à presença de poucos organismos nas amostras, por isso sua especificidade e sensibilidade são muito altas. Isto faz com que teste por DNA através de PCR constitua um método muito mais acurado e avançado para pesquisas e fins diagnósticos que testes sorológicos convencionais (Barlough et al. 1995, Reubel et al. 1998, Madigan \& Pusterla 2000, Bermann et al. 2002).

Este estudo visa a realização de uma investigação clínica em equinos de esporte e tração (carroceiros), comparando os valores obtidos em exames hematológicos, levando-se em consideração diferenças como características nutricionais, estado de higidez e tipo de atividade realizada, e, ao mesmo tempo, visa comparar as diferentes técnicas de pesquisa de hematozoários, como esfregaço sanguíneo e PCR. 


\section{MATERIAL E MÉTODOS}

Foram utilizados 30 equinos, com idade acima de 2 anos, 8 machos e 7 fêmeas para cada grupo experimental, sendo 15 integrantes do Grupo Tração (GT), correspondendo a equinos de tração (carroceiros) em atividade e 15 pertencentes ao Grupo de Esporte (GE), correspondendo a equinos de esporte em atividade hípica, situados na região de Pirassununga/SP. Os animais em estudo foram pesados, avaliados clinicamente e informações foram colhidas junto aos proprietários relacionadas ao tipo e quantidade de alimento que recebiam e atividade física que realizavam.

Foi realizada colheita de sangue da veia jugular de todos os animais, de ambos os grupos experimentais, para realização de exame hematológico e dosagem de fibrinogênio plasmático (técnica da precipitação por aquecimento), com intuito de traçar um perfil hematológico para cavalos de tração e cavalos atletas, correlacionando os resultados com a higidez, nutrição e atividade física desenvolvida pelos animais.

Foram realizadas colheitas de sangue para realização de esfregaços sanguíneos pelos métodos de esfregaço da gota do coágulo, esfregaço de sangue periférico e esfregaço de sangue da veia jugular, com intuito de comparar as diferentes técnicas de esfregaço no diagnóstico das hemoparasitoses. Para tanto, no método esfregaço da gota do coágulo, foram recolhidos $5 \mathrm{~mL}$ de sangue da veia jugular em tubo sem anticoagulante, aguardou-se a formação do coágulo, retirando-o do plasma. Após secagem da superfície externa do coágulo em papel absorvente, cortou-se o coágulo em fragmentos de $1 \mathrm{~cm}$ e utilizou-se da gota de sangue que fluiu da superfície seccionada para confecção do esfregaço (Stobbe 1990, Stobbe et al. 1992, Dantas et al. 2011). Para o método de esfregaço de sangue periférico, foi puncionada a ponta da orelha dos animais e para o método esfregaço de sangue da veia jugular, foi puncionada a veia jugular dos equinos. Após secagem dos esfregaços, os mesmos foram fixados em álcool metílico e corados pelo Rosenfeld (Birgel 1982). As lâminas foram examinadas com aumento de 100 vezes em toda sua extensão, observando-se a presença de hemocitozoários e a conformação dos parasitas intraeritrocitários e ou intraleucocitários, além de buscar a presença de hematozoários livres na circulação.

Da mesma forma, foram colhidos $10 \mathrm{~mL}$ de sangue da veia jugular, em tubo com EDTA, dos 30 equinos previamente selecionados (GT, $n=15$ e GE, $n=15$ ). As amostras foram identificadas e mantidas refrigeradas a $4^{\circ} \mathrm{C}$. Na sequência, as amostras de sangue foram submetidas ao protocolo de extração de DNA genômico, com kit comercial (Wizard® Genomic DNA Purification Kit, Promega Corp., Madison, WI, USA), seguindo instruções do fabricante. Elas foram testadas individualmente para Theileria equi (Babesia equi), Babesia caballi, Anaplasma phagocytophilum (Ehrlichia equi) e Ehrlichia risticcii (Neoricketsia risticii). As reações para detectar DNA dos citados hemoparasitas consistiram de PCR em tempo real.

As amostras que apresentaram fragmentos amplificados foram purificadas usando-se o kit comercial Wizard ${ }^{\circledR}$ Genomic DNA Purification Kit (Promega Corp., Madison, WI, USA), seguindo instruções do fabricante e, em seguida, foram submetidas ao sequenciamento genético utilizando-se kits comerciais Genesig ${ }^{\circledR}$ (Primerdesign Ltd, United Kingdom), de acordo com instruções do fabricante. Todos os kits comerciais utilizados para pesquisa de hematozoários por PCR em tempo real são compostos pelo primer específico para o hemoparasita/probe mix, padrão para controle positivo para o hemoparasita em teste, controle negativo (RNAse) DNAse free water), tampão para preparo do padrão e controle de extração interna de DNA.

Para pesquisa de Babesia caballi utilizou-se Genesig Advanced Kit Babesia caballi 18S ribosomal RNA gene; para Theileria equi utilizou-se Genesig Advanced Kit Theileria equi Equi merozoite antigen1 (ema-1) gene; para Anaplasma phagocytophilum utilizou-se Genesig Advanced Kit Anaplasma phagocytophilum major surface protein 4 (msp4) gene; e para Ehrlichia risticii utilizou-se Genesig Advanced Kit Ehrlichia genus 16S ribosomal RNA (18S) gene. Os kits destinam-se a ter o mais amplo perfil de detecção possível, mantendo-se específico para o genoma pesquisado. Os primers e as sequências de sondas dos kits possuem 100\% de homologia com uma ampla gama de sequências do genoma dos hemoparasitas pesquisados, com base numa análise bioinformática abrangente.

As reações foram realizadas utilizando-se $25 \mu \mathrm{l}$, sendo $5 \mu \mathrm{l}$ de DNA extraído. Para amplificação, protocolos de ciclos de PCR em dois passos foram conduzidos, sendo $95^{\circ} \mathrm{C}$ por 2 minutos, seguido de 45 ciclos de $95^{\circ} \mathrm{C}$ por 10 segundos e $60^{\circ} \mathrm{C}$ por 1 minuto. Os dados de fluorescência foram adquiridos ao final de cada passo de anelamento. 0 experimento foi conduzido utilizando-se o aparelho de PCR em tempo real BIOER LineGene 9600 (Hangzhou bori Technology Co., Ltd).

As variáveis hematológicas foram submetidas a analise de normalidade dos resíduos pelo teste de Kolmogorov-Smirnov. As variáveis que não atenderam às premissas de normalidade foram submetidas à transformação. Os dados originais ou transformados, quando este procedimento foi necessário, foram submetidos à análise de variância na comparação entre grupos. A diferença nas prevalências dos hemoparasitas foram comparadas usando-se o teste de Fischer. A metodologia utilizada para realização do diagnóstico das hemoparasitoses (PCR ou esfregaço sanguíneo) foram comparadas pelo teste de Kruskal-Wallis. Em todas as análises estatísticas, o nível de significância considerado foi de 5\%.

\section{RESULTADOS}

Avaliando-se os dados colhidos individualmente, verificou-se que no Grupo Tração (GT), o peso dos animais variou de 220 a $430 \mathrm{~kg}(336 \pm 51 \mathrm{~kg})$, idade entre 2,5 e 24 anos (18,4\% de 2-5 anos, 28,6\% de 6-10 anos, 42,8\% de 11-15 anos, $8,2 \%$ de $16-20$ anos e $2 \%$ com mais de 20 anos) e intensidade de trabalho entre 4 e 40 horas semanais $(26,9 \%$ de $4-10$ horas, $59,6 \%$ de $11-20$ horas, $11,5 \%$ de $21-30$ horas e 1,9\% de 31-40 horas). Da mesma forma, verificou-se que no Grupo Esporte (GE), o peso variou de 350 a 630 $\mathrm{kg}(490 \pm 56 \mathrm{~kg})$, idade de 4 a 17 anos $(16,3 \%$ de $2-5$ anos, $40,8 \%$ de $6-10$ anos, $32,6 \%$ dfe $11-15$ anos e $10,2 \%$ de $16-$ 20 anos) e intensidade de trabalho entre 16 e 24 horas semanais (83,6\% de $11-20$ horas e $16,3 \%$ de $21-30$ horas). Pode ser observado que os animais do GT são alimentados com uma mistura alimentos, entre eles, capim triturado ou não, cana-de-açúcar triturada ou não, milho, rolão de milho, palha de milho, quirela de milho, farelo de milho, farelo de trigo, aveia, amido, feno, pasto, entre outros. Já os animais do GE são alimentados apenas com feno e concentrado (ração para equinos). Nenhum dos animais, de ambos os grupos experimentais, recebia sal mineral para equinos.

Os Quadros 1, 2 e 3 apresentam os valores médios de eritrograma, leucograma, proteínas totais e fibrinogênio obtidos em cada grupo experimental. No total dos equinos estudados, 23 (76,7\%) apresentaram contagem de hemácias abaixo do valor de referência, dentre eles, 15 são equinos de tração (100\% dos total de animais do GT) e 8 animais de esporte (53,3\% do total de animais do GE). Individualmente, os 15 animais pertencentes ao Grupo Tração (100\% 
Quadro 1. Comparação das médias e desvio padrão dos valores do exame da série vermelha e plaquetas de equinos de tração (GT; $n=15$ ) e equinos de esporte (GE; $n=15$ )

\begin{tabular}{lccccccc}
\hline Grupo & $\begin{array}{c}\text { Hemácias* } \\
\left(\mathrm{x} 10^{6} / \mathrm{uL}\right)\end{array}$ & $\begin{array}{c}\text { Hemoglobina* } \\
(\mathrm{g} / \mathrm{dL})\end{array}$ & $\begin{array}{c}\text { Hematócrito* } \\
(\%)\end{array}$ & $\begin{array}{c}\text { VCM } \\
(\mathrm{fL})\end{array}$ & $\begin{array}{c}\text { HCM } \\
(\mathrm{pg})\end{array}$ & $\begin{array}{c}\text { CHCM } \\
(\mathrm{g} / \mathrm{dL})\end{array}$ & $\begin{array}{c}\text { plaquetas } \\
\left(\mathrm{x} 10^{3} / \mathrm{uL}\right)\end{array}$ \\
\hline Tração & $5,64 \pm 0,85$ & $9,88 \pm 1,05$ & $27,27 \pm 3,03$ & $48,77 \pm 3,61$ & $17,62 \pm 1,47$ & $36,24 \pm 1,47$ & $191,28 \pm 40,59$ \\
Esporte & $7,00 \pm 0,89$ & $12,15 \pm 1,54$ & $35,13 \pm 4,69$ & $50,38 \pm 2,60$ & $17,36 \pm 0,77$ & $34,59 \pm 1,17$ & $149,13 \pm 51,23$ \\
Valores de referência* & $6,8-12,9$ & $11-19$ & $32-53$ & $32-59$ & $12-20$ & $31-39$ & $100-250$ \\
\hline
\end{tabular}

* Diferença estatística $(\mathrm{p}<0,05)$; Meyer \& Harvey (2004).

Quadro 2. Comparação das médias e desvio padrão dos valores do exame da série branca de equinos de tração (GT; $n=15)$ e equinos de esporte (GE; $n=15$ )

\begin{tabular}{lcccccc}
\hline Grupo & $\begin{array}{c}\text { Leucócitos } \\
\left(\mathrm{x} 10^{3} / \mathrm{uL}\right)\end{array}$ & $\begin{array}{c}\text { Basófilos* } \\
(/ \mathrm{uL})\end{array}$ & $\begin{array}{c}\text { Eosinófilos* } \\
(/ \mathrm{uL})\end{array}$ & $\begin{array}{c}\text { Neutrófilos segmentados* } \\
(/ \mathrm{uL})\end{array}$ & $\begin{array}{c}\text { Linfócitos* } \\
(/ \mathrm{uL})\end{array}$ & $\begin{array}{c}\text { Monócitos } \\
(/ \mathrm{uL})\end{array}$ \\
\hline Tração & $7,8 \pm 2,5$ & $100 \pm 112$ & $300 \pm 218$ & $4800 \pm 2078$ & $2500 \pm 987$ & $200 \pm 124$ \\
Esporte & $6,9 \pm 1,13$ & $40 \pm 60$ & $370 \pm 290$ & $4240 \pm 900$ & $2100 \pm 700$ & $150 \pm 100$ \\
Valores de referência* & $5,4-14,3$ & $0-290$ & $0-1000$ & $2260-8580$ & $1500-7700$ & $0-1000$ \\
\hline
\end{tabular}

* Diferença estatística $(\mathrm{p}<0,05)$; Meyer \& Harvey (2004).

do total de animais do GT) apresentaram hematócrito e hemoglobina abaixo dos valores de referência para a espécie, enquanto que no Grupo Esporte, três equinos (20\% do total de animais do GE) apresentaram valores de hemoglobina e 4 equinos (26,7\% do total de animais do GE) apresentaram valores de hematócrito abaixo dos valores de referência para a espécie. Na avaliação das médias dos valores apresentados pelos grupos estudados, a contagem de hemácias, hemoglobina e hematócrito encontraram-se abaixo dos considerados fisiológicos para a espécie apenas no GT, assim como na comparação entre os grupos, em que os valores destes parâmetros hematológicos foram considerados significativamente menores no GT $(\mathrm{p}<0,05)$.

Quanto ao leucograma, não foram observadas alterações na avaliação das médias dos valores apresentados pelos grupos estudados. Individualmente, no GT, três equinos (20\% do total de animais do GT) apresentaram linfopenia, um equino $(6,7 \%$ do total de animais do GT) apresentou neutrofilia, por aumento no número absoluto de neutrófilos segmentados e um equino $(6,7 \%$ do total de animais do GT) apresentou basofilia; no GE, um animal $(6,7 \%$ do total de animais do GE) apresentou leucopenia, três equinos (20\% do total de animais do GT) apresentaram linfopenia e um animal apresentou eosinofilia $(6,7 \%$ do total de animais do GE). Na comparação entre os grupos, os animais do GT apresentaram contagem significativamente maior de neutrófilos, linfócitos e basófilos e menor de eosinófilos $(\mathrm{p}<0,05)$.

No total de equinos estudados, 11 animais do GT $(73,3 \%)$ apresentaram valores de fibrinogênio acima do considerado fisiológico para a espécie, enquanto que nenhum dos equinos do GE apresentou alteração deste parâmetro. Na comparação entre os grupos, os equinos do GT apresentaram valores de fibrinogênio significativamente maiores que os animais do GE $(\mathrm{p}<0,05)$. Todos os equinos apresentaram concentrações plasmáticas de proteínas dentro do considerado fisiológico, exceto um animal do GE $(6,7 \%)$ que apresentou hipoproteinemia.

Na observação dos esfregaços sanguíneos, dos 30 equinos avaliados, foram revelados 10 resultados positivos para Theileria equi $(33,33 \%)$, sendo 6 equinos (40\%)
Quadro 3. Comparação das médias e desvio padrão dos valores de proteína plasmática e fibrinogênio de equinos de tração (GT; $n=15)$ e equinos de esporte (GE; $n=15$ )

\begin{tabular}{lcc}
\hline Grupo & Proteína plasmática $(\mathrm{g} / \mathrm{dl})$ & Fibrinogênio* \\
\hline Tração & $7,26 \pm 0,33$ & $0,62 \pm 0,27$ \\
Esporte & $6,76 \pm 0,46$ & $0,27 \pm 0,1$ \\
Valores de referência* & $5,8-8,7$ & $0,12-0,49$
\end{tabular}

* Diferença estatística $(\mathrm{p}<0,05)$; Meyer \& Harvey (2004).

Quadro 4. Apresentação do número de equinos (n) e porcentagem do total avaliado(\%) que apresentaram resultados positivos para hemoparasitas, pelas técnicass de esfregaço sanguíneo e PCR, em ambos grupos experimentais, Grupo Tração (GT, n=15) e Grupo Esporte (GE, n=15)

\begin{tabular}{|c|c|c|c|c|c|c|c|c|}
\hline \multirow[t]{2}{*}{ Patógenos } & \multicolumn{2}{|c|}{$\begin{array}{l}\text { Esfregaço } \\
\text { sanguíneo } \\
\text { GT (n=15) }\end{array}$} & \multicolumn{2}{|c|}{$\begin{array}{c}\text { PCR* } \\
\text { GT }(n=15)\end{array}$} & \multicolumn{2}{|c|}{$\begin{array}{l}\text { Esfregaço } \\
\text { sanguíneo } \\
\text { GE (n=15) }\end{array}$} & \multicolumn{2}{|c|}{$\begin{array}{c}\text { PCR* } \\
\text { GE }(n=15)\end{array}$} \\
\hline & $\mathrm{n}$ & $\%$ & $\mathrm{n}$ & $\%$ & $\mathrm{n}$ & $\%$ & $\mathrm{n}$ & $\%$ \\
\hline \multicolumn{9}{|l|}{ Infecção única } \\
\hline T. equi & 6 & 40 & 3 & 20 & 4 & 26,7 & 2 & 13,3 \\
\hline $\begin{array}{l}\text { B. caballi } \\
\text { Infecção mista }\end{array}$ & 0 & 0 & 1 & 6,7 & 0 & 0 & 5 & 33,3 \\
\hline T. equi + B. caballi & 0 & 0 & 11 & 73,3 & 0 & 0 & 8 & 53,3 \\
\hline Total positivos & & 40 & & 100 & & 26,7 & & 100 \\
\hline
\end{tabular}

pertencentes ao GT e 4 equinos $(26,67 \%)$ pertencentes ao GE. Não foi observada diferença significativa entre as técnicas de pesquisa de hematozoários, seja pela técnica do esfregaço sanguíneo realizados com sangue da veia jugular, sangue periférico (capilar sanguíneo) e pelo teste da gota do coágulo $(\mathrm{p}<0,05)$. Nas amostras colhidas dos equinos do GT, observou-se que $100 \%$ dos equinos (15 animais) foram positivos no PCR para hemoparasitoses, sendo que $6,67 \%$ (1 equino) apresentaram resultados positivos para Babesia caballi, 20\% (3 equinos) apresentaram resultados positivos para Theileria equi e 73,33\% (11 equinos) apresentaram resultados positivos para ambos os hemoparasitas, Babesia caballi e Theileria equi. Vale ressaltar que esses equinos estavam trabalhando, diariamente, puxando carroças. Em relação aos equinos do GE, o exame de PCR revelou a presença de hemoparasitas em $100 \%$ dos ani- 
mais selecionados (15 cavalos), sendo que 33,3\% apenas Babesia caballi (5 animais), 13,3\% apenas Theileria equi (2 animais) e 53,3\% dos animais (8 cavalos) apresentavam os dois hemoparasitas no sangue colhido (Babesia caballi e Theileria equi). Vale ressaltar que todos estes animais estavam em treinamento e nenhum dos proprietários suspeitava da possibilidade de apresentarem hemoparasitoses. Foi encontrada diferença estatística na metodologia utilizada para pesquisa de hematozoários, de maneira que a detecção de ambos hemoparasitas pela técnica de PCR foi significativamente maior quando comparada com a técnica de esfregaço sanguíneo ( $\mathrm{p}<0,05$; Quadro 4). Não foram encontradas diferenças significativas na prevalência de Theileria equi e Babesia caballi $(\mathrm{p}<0,05)$.

Todos os equinos do grupo tração e do grupo esporte apresentaram resultados negativos para Anaplasma phagocytophilum (Ehrlichia equi) e Ehrlichia risticcii (Neoricketsia risticii).

\section{DISCUSSÃO}

Na clínica médica de equinos, explora-se o perfil hematológico do animal, geralmente, com a finalidade de encontrar alterações que não foram constatadas ao exame clínico. Atualmente, o médico veterinário se depara com resultados de exames hematológicos que devem ser comparados com valores de referência para a espécie adaptados da bibliografia internacional, baseados em exames de cavalos hígidos, com clima, nutrição e atividade física padronizados. Este fato faz com que surjam dúvidas quanto ao verdadeiro significado clínico dos resultados hematológicos obtidos com os equinos atendidos nas diferentes regiões do Brasil, em diferentes condições nutricionais e de higidez, realizando atividades físicas diversas. Este estudo apresenta uma avaliação comparativa dos valores obtidos em exame hematológico, em equinos de esporte e tração (carroceiros), levando-se em consideração diferenças como características nutricionais, estado de higidez e tipo de atividade realizada.

Avaliando-se os dados colhidos neste estudo, verifica-se que os equinos do grupo tração possuíam em sua maioria maior idade que os equinos do grupo esporte e apresentavam média de intensidade de trabalho similares aos equinos de esporte, embora a qualidade nutricional estivesse aquém ao ideal, o que reflete em menor peso dos animais e, possivelmente, no perfil hematológico de anemia. Ressalta-se a importância de uma avaliação conjunta dos dados hematológicos com o histórico do animal, para que se realize interpretações adequadas dos resultados obtidos. Neste estudo, a realização de exame hematológico, comparando equinos de esporte com equinos de tração, revelou um perfil com menor contagem de hemácias, hemoglobina e hematócrito para os equinos carroceiros, apresentando valores abaixo do considerado fisiológico para a espécie equina segundo a literatura (Meyer \& Harvey 2004). Porém, trata-se da média de 15 equinos que estão diariamente em atividade de tração e que recebem alimentos de baixa qualidade nutricional. Sabe-se que o perfil hematológico é uma ferramenta capaz de demonstrar sobrecarga de trabalho, treinamento e nutrição inadequados (Veiga et al. 2006, Kowal et al. 2006.) No caso em estudo, é provável que a qualidade e quantidade de alimentos recebidos pelos equinos carroceiros seja inferior ao exigido para o nível de exercício a que são submetidos, e, associado aos resultados positivos de PCR para hemoparasitas, sejam responsáveis pelo quadro de anemia apresentado por $100 \%$ dos equinos estudados no Grupo Tração. Ressalta-se a importância de uma nutrição adequada ao tipo de exercício e idade do animal, visto que no Grupo Esporte apenas 53,3\% dos animais apresentavam quadro hematológico de redução do número de hemácias, $26,7 \%$ redução de hematócrito e $20 \%$ redução de hemoglobina, embora $100 \%$ fossem positivos no PCR para hemoparasitoses.

Vale ressaltar que, após diagnóstico positivo para hemoparasitoses por PCR em $100 \%$ dos equinos estudados, de ambos os grupos experimentais, apenas os equinos do Grupo Tração (GT) apresentaram valores médios de hemácias, hemoglobina e hematócrito abaixo dos valores de referência, caracterizando um quadro de anemia, assim como a elevação de fibrinogênio, que sinaliza presença de processo inflamatório. Já as amostras colhidas dos equinos do Grupo Esporte (GE) não evidenciaram valores médios hematológicos ou de fibrinogênio alterados, comparando-se com os valores de referência considerados fisiológicos a espécie. Este aspecto é de suma importância, demonstrando que resultados hematológicos considerados dentro do fisiológico podem ser resultados de exames de animais que apresentam hemoparasitoses e estão em atividade física/esportiva plena, o que justifica as reagudizações da enfermidade, frequentemente observada em equinos submetidos às situações de estresse. Provavelmente, trata-se de animais que apresentam a forma crônica da afecção, representando um risco para transmissão a outros animais e para sua própria saúde, além da reconhecida queda de performance (Laus et al. 2015).

A pesquisa de hematozoários em equinos, muitas vezes, apresenta resultados conflitantes entre o quadro clínico apresentado pelo animal e o resultado laboratorial, levantando a hipótese de que a técnica de pesquisa de hematozoários seja a responsável por falhas diagnósticas. Para diagnóstico de hemoparasitoses, na maioria das ocasiões, une-se a clínica apresentada pelo animal, a métodos complementares de diagnóstico, como exame hematológico, que revela baixos valores de hemácias, hematócrito e hemoglobina e a pesquisa de hematozoários por esfregaço sanguíneo, que embora seja uma técnica de subjetiva e de baixa sensibilidade para detectar hemoparasitas, principalmente em cavalos com baixa parasitemia, é simples e de baixo custo, sendo uma ferramenta complementar útil para diagnósticos a campo (Laus et al. 2015, Posada-Guzmán et al. 2015). A pesquisa de hematozoários por PCR é altamente eficiente, uma vez que detecta reduzidas taxas de parasitemia, determinando animais persistentemente infectados e cronicamente infectados. Porém, devido ao custo elevado, o emprego desta técnica não é a opção da maioria dos médicos veterinários clínicos de equinos (Posada-Guzmán et al. 2015). Sendo assim, este estudo apresenta uma comparação das técnicas de esfregaço sanguíneo e PCR para diagnóstico de hemoparasitas, em equinos de esporte e tração (carroceiros), e revela que embora os animais pos- 
sam parecer hígidos clinicamente e, até mesmo, apresentar valores hematológicos dentro dos valores de referência utilizados como fisiológico para a espécie, podem possuir hemoparasitas no organismo, o que certamente influi na higidez e desempenho do animal. Além disso, esses animais podem atuar como fontes de hemoparasitas para carrapatos, aumentando a probabilidade de transmissão a outros animais (Laus et al. 2015). Estes são fatos que devem ser considerados na escolha da técnica de diagnóstico para hemoparasitoses dentro de uma propriedade.

Verifica-se, por meio dos resultados apresentados, que os esfregaços sanguíneos, mesmo que realizados por diferentes técnicas de pesquisa de hematozoários, revelaram resultados falsos negativos em animais de ambos grupos experimentais. Observa-se, também, que infecções mistas de hemoparasitas, muitas vezes não são diagnosticadas como tal. Neste estudo, os esfregaços revelaram apenas infecção por Theileria equi (GT, n=6 e GE, n=4), sendo que o PCR confirmou que algumas delas seriam, na verdade, infecções mistas (Theileria equi e Babesia caballi).

Com relação às diferentes técnicas de esfregaço sanguíneo, embora Stobbe $(1990,1992)$ e Dantas et al. (2011) afirmem que o teste da gota do coágulo expresse um excelente método de diagnóstico de hemoparasitas em equinos, neste estudo, não foi observada diferença entre as técnicas de pesquisa de hematozoários, seja pela técnica do esfregaço sanguíneo realizado com sangue da veia jugular, sangue periférico (capilar sanguíneo) e pelo teste da gota do coágulo. Além disso, nos esfregaços realizados pelo teste da gota do coágulo foram observadas áreas de lise celular que prejudicaram a avaliação das lâminas, além de alterações morfológicas, como por exemplo, eritrofagocitose, lise de leucócitos e de hemácias, vacúolos citoplasmáticos, manchas de Gumprecht, segmentos nucleares soltos, entre outros. Esses artefatos prejudicaram a avaliação, não sendo considerado, neste estudo, o esfregaço da gota de coágulo um método prático e confiável, podendo apresentar falsos negativos ou falsos positivos.

Por outro lado, a associação do exame hematológico a uma avaliação clínica detalhada e ao exame de PCR permitiu que se obtivessem diagnósticos definitivos precisos quanto à pesquisa de hematozoários (Laus et al. 2015). 0 exame de PCR se trata de uma prova confiável, que diagnostica a infecção em fase aguda ou crônica, em animais com alta ou baixa parasitemia, uma vez que busca a presença do DNA do hemoparasita na amostra de sangue (Barlough et al. 1995, Reubel et al. 1998, Madigan \& Pusterla 2000, Bermann et al. 2002, Parra 2009, Leal et al. 2011, Malekifard et al. 2014, Posada-Gusmán et al. 2015). Neste estudo ficou demonstrada a maior sensibilidade do método de PCR, visto que $100 \%$ dos equinos (30 animais) apresentaram resultados positivos para hemoparasitas pela técnica molecular, enquanto que o esfregaço sanguíneo revelou 33,3\% (10 equinos) de positivos.

Estabelece-se claramente a importância das provas como o PCR, que diagnostica infecções agudas e crônicas, para o diagnóstico correto e conclusivo das hemoparasitoses, mesmo que os esfregaços sanguíneos apresentem resultados negativos. Baseado na sintomatologia clínica apresentada pelo animal, associado ao exame hematológico e presença de carrapatos, deve-se sempre sugerir a realização de provas mais sensíveis, como PCR, para que se forneça um diagnóstico definitivo correto para o proprietário do animal. Verifica-se, então, com este estudo, que muitos dos diagnósticos de ausência de hemoparasitose por exame hematológico e ou esfregaço sanguíneo são errôneos, devido à baixa sensibilidade da técnica e podem repercutir em falha no tratamento ou disseminação dos hemoparasitos e das hemoparasitoses. Ressalta-se, então, a importância de exames como o PCR na elaboração de diagnóstico definitivo.

Agradecimentos.- À Fundação de Amparo à Pesquisa do Estado de São Paulo (FAPESP).

\section{REFERÊNCIAS}

Abedi J., Razmi G., Seifi H. \& Naghibi A. Molecular and serological detection of Theileria equi and Babesia caballi infection in horses and ixodid ticks in Iran. 2014. Ticks Tick Borne Dis. 5:239-244.

Barlough J.E., Madigan J.E., Derock E., Dumler J.S. \& Bakken J. 1995. Protection against Ehrlichia equi is conferred by prior infection with the human granulocytotropic erlichia (HGE Agente). J. Clin. Microbiol. 33:3333-3334.

Bashiruddin J.B., Camma C. \& Rebelo E. 1999. Molecular detection of Babesia equi and Babesia caballi in horse blood by PCR amplification of part of the 16SrRNA gene. Vet. Parasitol. 84:75-83.

Becker R.C., Torres A. J., Nizoli L.Q., Ferraz A. \& Nogueira C.E.W. 2007. Prevalência sorológica de babesiose equina em cavalos da Brigada Militar de Pelotas/RS. Anais 16을 Congresso de Iniciação Científica e 9o Encontro da Pós-Graduação, Pelotas, RS, p.1. (Resumo)

Bermann F., Davoust B., Fournier P.E., Brisou-Lapointe A.V. \& Brouqui P. 2002. Erhlichia equi (Anaplasma phagocytophila) infection in an adult horse in France. Vet. Rec. 22:787-788.

Dantas M.O., Dias L.M.M.S., Moura A.C.F., Seidel S.R.T., Vargas C.R. \& Silva Neto J.J. 2011. Pesquisa de hematozoários mediante avaliação do esfregaço da gota do coágulo e sangue periférico em equinos de equitação. Anais 38 Conbravet, Florianópolis, SC, p.1-3. (Resumo expandido)

Everton E.B., Meneses A.M.C., Marques J.R.F., Freitas N.M.S., Fragoso D.S., Mangas T.P. \& Lima D.J.S. 2011. Valores hematológicos de equinos da raça Puruca. Anais 9o Seminário Anual de Iniciação Científica da UFRA: a pesquisa e a ética na formação profissional, Belém, PA, p.1-4. (Resumo expandido)

Golynski A.A., Fernandes K.R., Baldani C.D., Golynski A.L., Madeiro A.S., Machado R.Z., Botteon P.T.L. \& Massard C.L. 2008. Estudo soroepidemiológico da Babesia equi em eqüinos do Rio Grande do Sul, pelos testes de imunofluorescência indireta e ELISA. Revta Bras. Parasitol. Vet. 17:317321.

Kowal R. J., Almosny N.R.P., Cascardo B., Summa R.P. \& Cury L.J. 2006. Avaliação dos valores hematológicos em cavalos (Equus caballus) da raça Puro-Sangue-Inglês (PSI) submetidos a teste de esforço em esteira ergométrica. Revta Bras. Ciênc. Vet. 13:25-31.

Laus F., Spaterna A., Faillace V., Veronesi F., Ravagnan S., Beribé F., Cerquetella M., Maligrana M. \& Tesei B. 2015. Clinical investigation on Theileria equi and Babesia caballi infections in Italian donkeys. BMC Vet. Res. 11:100-107.

Leal D.C., Madruga C.R., Matos P.F., Souza B.M.P.S. \& Franke C.R. 2011. Evaluation of PCR and multiplex PCR in relation to nested PCR for diagnosing Theileria equi. Pesq. Vet. Bras. 31:575-578.

Madigan J.E. \& Pusterla N. 2000. Erhlichial diseases. Vet. Clin. North Am. 16:487-499.

Malekifard F., Tavassoli M., Yakhchali M. \& Darvishzadeh R. 2014. Detection of Theileria equi and Babesia caballi using microscopic and molecular methods in horses in suburb of Urmia, Iran. Vet. Res. Forum. 5:129133. 
Maroso J.A., Escobar A.W., Nizoli L.Q., Silva S.S., Lunge V.R., Simon D. \& Passos D.T. 2002. Comparação dos testes de imunofluorescência indireta (RIFI) e reação em cadeia da polimerase aninhada (Nested-PCR) no diagnóstico da infecção de equinos por Babesia equi. Revta Iniciação Cient. ULBra 1:25-30.

Meyer D.J. \& Harvey J.W. 2004. Veterinary Laboratory Medicine: Interpretation and Diagnosis. 3rd ed. W.B. Saunders, London. 368p.

Nizoli L.Q., Conceição F.R., Silva S.S., Dellagostin O.A. \& Leite F.P.L. 2006. Amplificação e clonagem do gene EMA-1 de Babesia equi. Anais 15 Congresso de Iniciação Científica e 8o Encontro da Pós-Graduação, Pelotas, RS, p.1. (Resumo)

Parra A.C. 2009. Investigação diagnóstica de doença concomitante Babesiose e Anaplasmose em rebanho equino, por técnicas de Nested PCR e c-ELISA ou ELISA indireto. Tese de Doutorado, Universidade de São Paulo, São Paulo, SP. 78p.

Paz e Silva F.M., Teixeira M.N., Lopes R.S. \& Araújo Júnior J.P. 2009. Erlichioses. Vet. Zootec. 16:290-302.

Posada-Guzmán M.F., Dolz G., Romero-Zúñiga J.J. \& Jiménez-Rocha A.E. 2015. Detection of Babesia caballi and Theileria equi in blood from equines from four indigenous communities in Costa Rica. Vet. Med. Intern. 2015:1-6.

Reubel G.H., Barlough J.E. \& Madigan J.E. 1998. Production and characterization of Erhlichia risticii, the agent of Potomac horse fever, from snails (Pleuroceridae: Juga spp.) in aquarium culture and genetic comparison to equine strains. J. Clin. Microbiol. 36:1501-1511.

Ribeiro C.R., Fagliari J.J., Galera P.D. \& Oliveira A.R. 2008. Hematological profile of healthy Pantaneiro horses. Arq. Bras. Med. Vet. Zootec. 60:492495.

Sakai R.K., Cordeiro M.D., Bicalho J.A.E., Baêta B.A. \& Fonseca A.H. 2009. Avaliação hematológica de equinos (Equus caballus) criados a pasto na Universidade Federal Rural do Rio de Janeiro, Campus Seropédica. Anais 9o Encontro Latino Americano de Pós-Graduação, São José dos Campos, SP, p.1-3. (Resumo expandido)

Salvagni C.A., Dagnone A.S., Gomes T.S., Mota J.S., Andrade G.M., Baldani C.D. \& Machado R.Z. 2010. Serologic evidence of equine granulocytic anaplasmosis in horses from central West Brazil. Revta Bras. Parasitol. Vet. 19:135-140.

Sgorbini M., Bonelli F., Nardoni S., Rocchigiani G., Corazza M. \& Mancianti F. 2015. Seroprevalence and molecular analysis of Babesia caballi and Theileria equi in horses from central Italy during a 10-year period. J. Eq. Vet. Sci. 35:865-868.

Stobbe N.S. 1990. Coágulo de sangue no diagnóstico de hematozoários, desenvolvimento e comparação entre técnicas. Dissertação de Mestrado, Faculdade de Veterinária, Universidade Federal Rural do Rio Grande do Sul, Porto Alegre.

Stobbe N.S., Chaplin E.L., Paiva M.G.S., Silva N.R.S., Araújo F.A.P. \& Fortes E. 1992. Diagnóstico de hemoparasitose através da técnica de distensão de gota de coágulo sanguíneo. Braz. J. Res. Anim. Sci. 29:390-393.

Veiga A.P.M., Lopes S.T.A., Franciscato C., Oliveira L.S.S. \& Merini L.P. 2006. Valores hematológicos, proteínas plasmáticas totais e fibrinogênio do cavalo crioulo - suas variações em relação ao sexo, idade e manejo. Acta Scient. Vet. 34:275-279. 